\title{
Editorials
}

\section{Alma-Ata 40th birthday celebrations and the Astana Declaration on Primary Health Care 2018}

\section{INTRODUCTION}

International governments, universities, and health and social care organisations celebrated the 40th anniversary of the AlmaAta Declaration in October 2018. AlmaAta ${ }^{1}$ was a landmark global commitment to primary health care (PHC), which conceptualised health, not only as provision of biomedical care, but also emphasised the importance of social and economic factors. This anniversary has been marked with the publication of the Astana Declaration in Kazakhstan 25-26 October 2018, ${ }^{2}$ which will contribute to events next year supporting universal health coverage' (UHC) and the 2030 Agenda for Sustainable Development Goals (SDG).

\section{BACKGROUND}

Primary care is positioned by the World Health Organization (WHO) as one important pillar of UHC. The three main principles of UHC are equity of access; ensuring health services are of sufficient quality to improve the health of recipients; and protection of patients from financialrisk resulting from healthcare access. The WHO Global Action Plan to achieve the 2030 Sustainable Development Goals ${ }^{3}$ promotes alignment of financing and resources; accountability for healthcare delivery; and accelerated progress to collectively bring together resources and expertise.

Alma-Ata 40th anniversary celebrations coincide with the 70th birthday of the NHS. Both have striven to promote PHC delivery which is universal (open to all); comprehensive (patients can present any problem or illness); and free at the point of access. Both celebrations, however, mark an important point in history at which the success and development of PHC might either flourish or perish.

\section{ARTICULATING PRIMARY HEALTH CARE IN 2018}

We know from many studies following the work of Barbara Starfield ${ }^{4}$ that effective

'This approach aims to maximise health and wellbeing across global society, rather than aiming to detect and treat all disease.

primary care enables efficient, costeffective, and high-quality healthcare delivery to those in need. Iona Heath has developed the concept of 'gatekeeping' in primary care at two levels, reflecting not only the interface at which a referral is made to another service, but also the process of negotiation and differentiation during patient consultations: navigating with patients between stressful experiences, illness, and medicalised disease. ${ }^{5}$ This highlights the balance required between identifying and treating patients' biomedical needs, while avoiding overdiagnosis, investigation, and treatment, ultimately prioritising patients above commercial needs. ${ }^{6}$ This approach aims to maximise health and wellbeing across global society, rather than aiming to detect and treat all disease. Richard Wilkinson and Kate Pickett ${ }^{7}$ have pioneered examination of the impact of social inequalities on both physical and mental wellbeing across all individuals in society, highlighting the impact of inequality on both rich and poor in relation to the existence of social and economic disparity.

\section{CONTEMPORARY CHALLENGES TO PRIMARY HEALTH CARE}

Alma-Ata states that, 'Primary health care reflects and evolves from the economic conditions and sociocultural and political characteristics of the country and its communities .... The influence of policy is crucial to consider here in relation to both international and national acceptance and implementation of the Alma-Ata principles and more recent Astana Declaration recommendations.

\section{"WWe need] to ensure that "empowerment" is not about distributed accountability to vulnerable patient groups, but rather authentic shared involvement in the organisation, enquiry, and delivery of health care.}

Astana includes both service and healthcare education priorities. Across both, the importance of collaboration and sharing of expertise and knowledge is emphasised, at both national and international levels. Many countries are, however, currently trying to deliver increasingly compartmentalised land often privatised) PHC systems, and promoting individualisation rather than collective responsibility for health. In combination with a global rise in nationalism, this provides significant challenges for the effective exchange and delivery of knowledge at local, national, and international levels.

\section{PATIENT PERSPECTIVES AND PARTICIPATION}

The Alma-Ata $1978^{1}$ states that the people have the right and duty to participate individually and collectively in the planning and implementation of their health care', already hinting at ways in which patient involvement might contribute to research and delivery of care. The more recent Astana $^{2}$ refers to supporting people in acquiring the knowledge, skills and resources needed to maintain their health or health of those for whom they care, guided by health professionals'. This guidance and support is crucial to attend to, in order to ensure that 'empowerment is not about distributed accountability to vulnerable patient groups, but rather authentic shared involvement in the organisation, enquiry, and delivery of health care.

\section{FUTURE HEALTHCARE PROFESSIONALS}

While the Astana declaration refers to information rather than personal continuity of care and the use of technologies in surveillance and delivery of care, it does also prioritise capacity building of healthcare professionals. Astana explicitly calls on the international community to minimise the existing international migration phenomena. This requires significant work 


\section{Healthcare professional training institutions need to attend not only to the social accountability of each school in relation to their own local patient population, but also the distribution and exchange of knowledge across borders.}

to maximise communication of globally relevant principles of $\mathrm{PHC}$ delivery, but also to make visible the variety of ways in which these are adapted and applied in different contexts. Healthcare professional training institutions need to attend not only to the social accountability of each school in relation to their own local patient population, but also the distribution and exchange of knowledge across borders.

Astana calls for a commitment to health 'across all sectors', referring to a 'Health in All Policies' approach. This has important implications for the design and delivery of $\mathrm{PHC}$ service and education, to ensure that relevant knowledge is connected across disciplines, and both work and curricula is designed to enable fluidity across disciplinary boundaries.

\section{CONCLUSION}

In summary, the global collaboration of individuals and countries represented within the Astana Declaration, and the reaffirmation of many Alma-Ata principles underpinning international PHC delivery, has to be encouraged as a positive step.
However, careful consideration is required to negotiate many of the ideological tensions which exist between ambitions towards comprehensive and equitable PHC, within today's political and social contexts. Finding ways to maximise patient- and interprofessional connectivity at local, national, and international levels, will help support opportunities for both the development and exchange of knowledge both within service delivery and the development of healthcare professional education.

\section{Sophie Park,}

GP and Associate Professor, Director Medical Education (Primary Care and Community), UCL

\section{Ruth Abrams,}

Research Assistant, UCL Medical School, Royal Free Campus, London.

\section{Provenance}

Freely submitted; not externally peer reviewed.

\section{Competing interests}

The authors have declared no competing interests.

DOI: https://doi.org/10.3399/bjgp19X702293 Medical School, Royal Free Campus, London.

\section{ADDRESS FOR CORRESPONDENCE}

Sophie Park

UCL Medical School, Royal Free Campus, Rowland Hill St, London NW3 2PY, UK.

\section{Email: sophie.park@ucl.ac.uk}

\section{REFERENCES}

1. World Health Organization (WHO). Declaration of Alma-Ata. 1978. http://umw.who.int/ publications/almaata_declaration_en.pdf (accessed 3 Apr 2019).

2. World Health Organization, United Nations Children's Fund (UNICEF). Global Conference on Primary Health Care: From Alma-Ata towards universal health coverage and the Sustainable Development Goals. 2018. https:// www.who.int/docs/default-source/primaryhealth/declaration/gcphc-declaration.pdf laccessed 3 Apr 2019)

3. World Health Organization. Global Action Plan for healthy lives and well-being for all. 2019. https://www.who.int/sdg/global-action-plan (accessed 3 Apr 2019).

4. Starfield B, Shi L, Macinko J. Contribution of primary care to health systems and health. Milbank Q 2005; 83(3): 457-502.

5. Heath I. Divided we fail. Clin Med (Lond) 2011: 11(6): 576-586.

6. Moynihan R, Doust J, Henry D. Preventing overdiagnosis: how to stop harming the healthy. BMJ 2012; 344: e3502.

7. Wilkinson RG, Pickett $K$. The spirit level: why more equal societies almost always do better London: Allen Lane, 2009. 


\section{Editorials}

\section{Strengthening general practice by extending specialty training?}

\section{DURATION OF TRAINING PROGRAMMES IN EUROPE}

European legislation obligates member states to have a full-time postgraduate GP specialty training for $\geq 3$ years, with a minimum of 6 months spent in general practice. Across Europe, GP specialty training varies from 3 years (for example, in the UK and the Netherlands) to 6 years (Finland), with training time in general practices varying between 6 months (Austria) and 4 years (Norway). Recently, across Europe a strong movement in favour of extending the minimum duration of GP specialty training from the current 3 years to 4 or even 5 years has developed. ${ }^{1,2}$ Supporters of this measure state that this will build the same level as specialty as other disciplines' and therefore strengthen GPs' standing across Europe.,3 This is important because a strong primary care is needed to have a high-quality healthcare system accessible for all citizens, in which GPs function as key stakeholders. ${ }^{5,6}$ However, not every country values GPs in this way. Across Europe GPs' positions vary from being a strong gatekeeper with free access for patients to easily accessible secondary care and paid GP visits. Another argument for extending the duration is that more time spent in training will give trainees greater exposure to real world setting', and therefore better developed competencies important for future GPs. ${ }^{2}$ Recently, extension of GP training programmes in Scotland and the West of Ireland reported positive results, whereby trainees from these programmes felt better prepared for independent practice. ${ }^{7.8}$ The extended period of general practice training in particular (2 years instead of 1) was valued by the trainees. Although we recognise that becoming a GP takes time and requires the mastery of a broad range of competencies, ${ }^{2,4}$ in this editorial we will argue that merely extending GP specialty training might not be the right measure to better prepare trainees or to enhance GPs' standing.

\section{DIFFERENCES IN TRAINEES' COMPETENCIES}

Individual competency development, rather than time spent in a training scheme, should determine the duration of a training programme. We have the following reasons to support this argument.

\section{trainees' capability to master competencies depends}

on context.

First, trainees differ with regard to obtained competencies prior to residency. For example, they may have gained previous experience as a junior doctor not in training. in a $\mathrm{PhD}$ programme, or in transferable work experience outside the medical field. These competencies can be developed further during their training, and this may even lead to a shortening of their time in training.

Second, trainees capability to master competencies depends on context.' Most postgraduate learning occurs in the workplace, where trainees learn 'by doing'. Clinical experiences are the foundation of trainees' learning: trainees depend on the availability of relevant experiences to master competencies. However, workplaces are chaotic environments and therefore do not guarantee that all necessary experiences are encountered. ${ }^{10}$ It is questionable whether mere exposure will truly lead to more successful learning. Therefore, it would be better to increase the educational value of these workplaces by critically looking at the relevance of the workplace for learning primary care skills. For example, the duration of training in a GP setting could be increased at the expense of hospital training. Alternatively, self-directed learning (SDL) could be promoted or faculty development programmes organised.

A third reason is that trainees differ in their ability to learn. ${ }^{11}$ To reach the full potential a workplace offers, trainees need to engage with their learning. This engagement depends, at least partly, on trainees' motivation and self-regulation abilities. ${ }^{12}$ Self-regulated learning focuses on setting learning goals, identifying and employing learning strategies to fulfil those goals, and reflecting on this process. Motivated trainees with well-developed self-regulation skills will learn faster and more deeply; however, not every trainee has the same motivation or abilities to regulate their learning. ${ }^{13}$ Hence, the time to learn the same competence differs between trainees and training settings.

These factors call into question the logic behind extending the GP specialty training to enhance the quality of GPs or better prepare trainees. Quality of time in practice should take priority over quantity, as the time it takes trainees to master competencies is variable. ${ }^{12}$

\section{CUSTOMISING THE CURRICULUM}

Duration of training should be based on educational needs; however, in recent history most decisions regarding time spent in training have been political in nature. ${ }^{14}$ For example, recent governmental regulations in the Netherlands forced medical specialty training to shorten their programmes by an average of 6 months in order to save costs. Of course, changing to a competencebased, time-variable GP specialty training is easier said than done, and will require time and funding..$^{15}$ To fully equip future GPs with the competencies needed in our modern, fast-changing healthcare systems a more personal, customisable curriculum is needed. ${ }^{16}$ Moreover, we have to acknowledge that learning does not stop at the end of specialty training. In our view, competency-based, time-variable training may help to create GPs who are lifelong learners, deliver high-quality care, and have a high standing in their healthcare systems.

As stated before, we believe that it is time to improve GPs' standing across Europe. Next to improving GP specialty training, this can be achieved with other measures, of which there are four components. First, it is important that students get acquainted with general practice at an early stage of their medical training. Therefore it is important to have a strong position in the pre-graduate curricula and this contributes to the positive view students have of GPs. ${ }^{17}$ Unfortunately, in some countries it is still possible to become a medical doctor without experience in a primary care setting. ${ }^{17}$ Second, as in many other specialty programmes, GP trainees should be educated in academic skills. A strong academic base and development of evidence-based guidelines will improve the quality of primary care. Third, GPs should be encouraged to keep up their knowledge 
"Quality should be prioritised over quantity. Deliberate use of time in training, with good-quality workplaces and coaching of trainees' SDL skills, can enhance the quality of a specialty training programme.

and skills by continuous professional development. This can be part of a revalidation system. Finally, strengthening the GP workforce can be accomplished by creating special fields of interest to extend primary care knowledge and organisation of care. Dutch GPs, for example, can develop themselves in a specific area (for example, emergency carel and become a GP with a special interest'. These GPs can support other GPs by consultation, lecturing, and contributing to the organisation of care in their field of specialisation.

\section{CONCLUSION}

In summary, we believe that imposing an extended GP programme will not automatically or necessarily lead to a betterqualified GP workforce. Quality should be prioritised over quantity. Deliberate use of time in training, with good-quality workplaces and coaching of trainees' SDL skills, can enhance the quality of a specialty training programme. Sometimes an extension or shortening is warranted, which should always be informed by GP trainees' educational needs. To strengthen the position of GPs, other measures, such as enhancing quality through revalidation, ensuring a strong academic standing, and developing reliable, high-quality guidelines, can be taken without changing European legislation regarding the minimum duration of GP specialty training.

\section{ADDRESS FOR CORRESPONDENCE}

\section{Sarah de Bever}

Amsterdam UMC, University of Amsterdam, Department of General Practice, Meibergdreef 11, room J2-113, 1105 AZ, Amsterdam, the Netherlands.

\section{Email: S.debever囚amc.uva.nl}

\section{Sarah de Bever,} University of Amsterdam, Department of General Practice/GP Specialty Training, Amsterdam, the Netherlands.

\section{Jettie Bont,}

Head, GP Specialty Training, Amsterdam UMC, University of Amsterdam, Department of General Practice/GP Specialty Training, Amsterdam, the Netherlands.

\section{Nynke Scherpbier,}

Head, Primary Care Specialty Training Department, Radboud Institute for Health Sciences, Department of Primary and Community Care, Radboud University Medical Center, Nijmegen, the Netherlands.

\section{Provenance}

Freely submitted; externally peer reviewed.

\section{Competing interests}

The authors have declared no competing interests.

DOI: https://doi.org/10.3399/bjgp19X702305
GP Trainee and PhD Student, Amsterdam UMC

\section{REFERENCES}

1. Rughani A, Riley B, Rendel S. The future of GP specialty training: enhanced and extended. $\mathrm{Br}$ J Gen Pract 2012; DOI: https://doi.org/10.3399/ bjgp12X648972.

2. O'Shea EE. Extension of training for general practice: a review of the evidence. Educ Prim Care 2009; 20(1): 15-20.

3. Zarbailov N, Wilm S, Tandeter H, et al. Strengthening general practice/family medicine in Europe - advice from professionals from 30 European countries. BMC Fam Pract 2017; 18(1): 80.

4. van Zwanenberg T, Pringle M, Smail S, et al. The case for strengthening education and training for general practice. Br J Gen Pract 2001; 51(466): 349-350.

5. Kringos D, Boerma W, Bourgueil Y, et al. The strength of primary care in Europe: an international comparative study. $\mathrm{Br} J$ Gen Pract 2013; DOI: https://doi.org/10.3399/ bjgp13X674422

6. Starfield B, Shi L, Macinko J. Contribution of primary care to health systems and health. Milbank Q2005; 83(3): 457-502

7. O'Shea EB. What's another year? A qualitative evaluation of extension of general practice training in the West of Ireland. Educ Prim Care 2009; 20(3): 159-166.

8. Agius S, Lewis B, Kirk B, et al. The perceived benefits of a two-year period of extended specialty training in general practice: the trainees' perspective. Educ Prim Care 2014; 25(1): 26-35

9. Goldie J, Morrison J. Situating general practice training in the general practice context. Br J Gen Pract 2012; DOI: https://doi.org/10.3399/ bjgp12X636245.

10. Teunissen PW, Kogan JR, Ten Cate O, et al. Learning in practice: a valuation of context in time-variable medical training. Acad Med 2018; 93: S22-S26.

11. Billett S. Learning through health care work: premises, contributions and practices. Med Educ 2016; 50(1): 124-131.

12. Ten Cate O, Gruppen LD, Kogan JR, et al. Time-variable training in medicine: theoretical considerations. Acad Med 2018; 93: S6-S11.

13. Nothnagle M, Anandarajah G, Goldman RE, et al. Struggling to be self-directed: residents paradoxical beliefs about learning. Acad Med 2011; 86(12): 1539-1544.

14. Ten Cate O. Competency-based postgraduate medical education: past, present and future. GMS J Med Educ 2017; 34(5): Doc69.

15. van Rossum TR, Scheele F, Sluiter HE, et al. Effects of implementing time-variable postgraduate training programmes on the organization of teaching hospital departments. Med Teach 2018; 40(10): 1036-1041.

16. Irby DM, Cooke M, O'Brien BC. Calls for reform of medical education by the Carnegie Foundation for the Advancement of Teaching: 1910 and 2010. Acad Med 2010; 85(2): 220-227.

17. Turkeshi E, Michels NR, Hendrickx K, Remmen $\mathrm{R}$. Impact of family medicine clerkships in undergraduate medical education: a systematic review. BMJ Open 2015; 5(8): e008265. 


\title{
Editorials
}

\section{Reducing risk following self-harm:}

\author{
the need for careful prescribing
}

\section{SELF-HARM AS A RISK FACTOR FOR SUICIDE}

Self-harm is the strongest risk factor for suicide.1,2 Globally, suicide is the second most common cause of death among 10 to 24-year-olds after road traffic incidents. ${ }^{3}$ Recent evidence indicates that the incidence of self-harm may be increasing among adolescents. ${ }^{4}$ Older people who self-harm have an increased suicidal intent, ${ }^{5}$ and, although repetition rates are low compared with middle-aged adults, self-harm is more often fatal in older adults. ${ }^{6}$

Tyrell et al ${ }^{7}$ identify antidepressants and analgesics as common drugs used by young people for self-poisoning. Overdose as a form of self-harm may be with prescriptiononly or sales-restricted drugs, often in combination with alcohol. ${ }^{8}$ Depression is also a key risk factor for suicide. ${ }^{9}$ Older adults with previously diagnosed comorbid mental and physical health conditions have an increased risk of self-harm. ${ }^{6.10}$

\section{THE INVERSE CARE LAW}

Recent evidence also suggests that the Inverse Care Law, ${ }^{11}$ whereby quantity or quality of healthcare service provision is inversely associated with the level of healthcare need, operates in the clinical management of self-harm in all age groups. Thus, self-harm incidence is elevated across the life-course in practice populations in

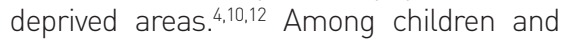
adolescents, ${ }^{4}$ and adults of working age, ${ }^{13}$ the incidence of self-harm is highest and the likelihood of referral to specialist services following self-harm is lowest in practices in the most deprived localities. Poisonings show a close relationship with deprivation, with the incidence of poisoning from all substances rising with increasing socioeconomic deprivation. ${ }^{7}$

\section{PATIENT SAFETY}

The National Institute for Health and Care Excellence (NICE) guidance for the longterm management of self-harm (CG133) 14 states that:

When prescribing drugs for associated mental health conditions to people who self-harm, take into account the toxicity of the prescribed drugs in overdose. In particular, do not use tricyclic antidepressants, such as dosulepin, because they are more toxic.'
The clinical importance of this statement is underlined by the fact that it was only one of three lamong a total of 57 recommendations in CG133) to be emphasised as a 'Do Not Do'recommendation. ${ }^{15}$

Despite this unequivocal warning, three recent studies in UK primary care patient cohorts, conducted by the same research team, demonstrated a high frequency of tricyclic antidepressant (TCA) prescribing, medication that is known to be potentially fatally toxic in overdose. $4,10,13,16$ Thus, $6.2 \%$ of adolescents (10-19 years), $49.6 \%$ of adults (15-64 years), ${ }^{13}$ and $11.8 \%$ of older adults $(\geq 65 \text { years })^{10}$ were prescribed a TCA within 12 months of their index self-harm episode. The proportion of cohort members aged 15-64 years prescribed a TCA did not fall discernibly across the 12-year observation period. ${ }^{13}$ Therefore, although CG133 was published in November 2011, from 20122013 8.8\% of cohort study participants still received this highly toxic antidepressant..$^{13}$ In that study, $70.4 \%$ of patients had a diagnosis of depression prior to their first TCA prescription, and $10.4 \%$ had a diagnosis of depression recorded on the same day as this prescription was issued. ${ }^{13}$ It is not known from these studies whether the TCAs were prescribed for depression or pain; although the latter would be unlikely in young people, it would be a possibility in older adults. Whatever the diagnostic label, however, the prescription of TCAs potentially compromises patient safety. In addition, the study reported the rate of opioid prescribing in the year following self-harm was $13.5 \%$ in adults of working age. ${ }^{13}$ Conversely, $10.9 \%$ of working age adults who had self-harmed had a psychiatric diagnosis documented, but were not subsequently prescribed medication or referred to specialist services. ${ }^{13}$ The observed trends for higher likelihood of psychotropic medication prescribing and lower likelihood of referral to specialist services with increasing levels of deprivation provides strong evidence for the Inverse Care Law. ${ }^{11}$

\section{IMPROVING CARE}

Elevated self-harm risk in the first 28 days of starting and stopping antidepressants emphasises the need for careful monitoring of patients during these periods. ${ }^{17}$ After self-harm in any patient, but particularly in an older adult, ${ }^{10}$ consideration of referral for psychological therapy or psychiatric opinion, and consideration of alternative medication, with particular avoidance of TCAs, might reduce the risk of escalating self-harm behaviour and associated mortality risk. Clinicians working with more deprived practice populations might particularly be reminded to consider alternative management options to prescribing.

The Safer Prescribing toolkit produced by the National Confidential Inquiry into Suicide and Safety in Mental Health ${ }^{18}$ highlights 3 points relevant to patient safety following self-harm:

1. encourage the safer prescribing of opioids;

2. ensure that there is a service in place for people with complex depression; and

3. be alert to people with markers of risk such as frequent consultation, multiple psychotropic medication, and specific drug combinations.

The toolkit suggests that GPs should be aware of the dangers associated with the prescribing of TCAs. ${ }^{18}$

\section{MANAGING PEOPLE FOLLOWING SELF- HARM}

Self-harm is a complex and often ingrained behaviour. ${ }^{14}$ People who have harmed themselves may be fearful of disclosing their behaviour due to stigma and shame (IM Troya et al, unpublished data, 2019). The clinician should show empathy for, and understanding of, the patient who has selfharmed, offering support and exploring the needs and expectations of the individual. This should include an exploration of mood, social factors, and risk of self-harm repetition, as well as consideration of the physical consequences of self-harm and injury. ${ }^{18}$ Consideration of referral for further care is also needed, particularly in more deprived areas, and has the potential to reduce the inequality of access to care for people who have harmed themselves. ${ }^{10,13}$ In addition, recognition of the role of thirdsector services in supporting people who self-harm is crucial and may plug the gap in service provision in more deprived areas (IM Troya et al, unpublished data, 2019).

Also vital is the need to prescribe carefully, particularly avoiding the use of TCAs, which can be lethal in overdose. ${ }^{16}$ While this is a clear 'Do Not Do' NICE 
recommendation, ${ }^{15}$ it is of concern that it is not being effectively implemented in practice. A simple alert on the primary care computer system would go a long way to reminding prescribers about the NICE 'Do Not Do' recommendation and the dangers of TCAs in people who have one or more self-harm episodes recorded in their notes.

The authors hope that this Editorial will highlight this patient safety concern and stark example of the Inverse Care Law, and draw attention to current recommendations for the management of people who have harmed themselves.

\section{Carolyn Anne Chew-Graham,}

Professor of General Practice Research, Research Institute, Primary Care and Health Sciences, Keele University, Keele; Midlands Partnership Foundation Trust, Stafford.

\section{Catharine Morgan,}

Research Associate, Division of Population Health, Health Services Research and Primary Care, University of Manchester, Manchester; Manchester Academic Health Sciences Centre (MAHSC).

Manchester.

\section{Roger T Webb,}

Professor of Mental Health Epidemiology, Manchester Academic Health Sciences Centre (MAHSC), Manchester; Centre for Mental Health and Safety, Division of Psychology and Mental Health, University of Manchester; NIHR Greater Manchester Patient Safety Translational Research Centre, Manchester.

\section{Angela Emery,}

Member of Keele Research User Group, Research Institute, Primary Care and Health Sciences, Keele University, Keele.

\section{Matthew J Carr}

Research Fellow, Manchester Academic Health Sciences Centre (MAHSC), Manchester; Centre for Mental Health and Safety, Division of Psychology and Mental Health, University of Manchester, Manchester.

\section{Evangelos Kontopantelis,}

Professor in Data Science and Health Services Research, Division of Population Health, Health Services Research and Primary Care, University of Manchester, Manchester; Manchester Academic Health Sciences Centre (MAHSC). Manchester.

\section{Alison R Yung,}

Professor of Psychiatry, Centre for Mental Health and Safety, Division of Psychology and Mental Health, University of Manchester, Manchester: Centre for Youth Mental Health, University of Melbourne, Parkville, Victoria, Australia.

\section{Darren M Ashcroft,}

Professor of Pharmacoepidemiology, Manchester Academic Health Sciences Centre (MAHSC), Manchester; NIHR Greater Manchester Patient
Safety Translational Research Centre, Manchester; Centre for Pharmacoepidemiology and Drug Safety, Division of Pharmacy and Optometry, University of Manchester, Manchester.

\section{Provenance}

Commissioned; not externally peer reviewed.

\section{ADDRESS FOR CORRESPONDENCE}

\section{Carolyn Anne Chew-Graham}

Research Institute, Primary Care and Health Sciences, Keele University, Keele, Staffordshire ST5 5BG, UK

Email: c.a.chew-grahamakeele.ac.uk

\section{Competing interests}

Carolyn Anne Chew-Graham, Catharine Morgan, Roger T Webb, Matthew J Carr, Evangelos Kontopantelis, and Darren M Ashcroft are co-authors of a number of papers cited in this manuscript. Angela Emery and Alison R Yung have declared no competing interests.

\section{Further information}

http://www.connectingwithpeople.org.

\section{REFERENCES}

1. World Health Organization (WHO). Preventing suicide: a global imperative. 2014. http://wnw. who.int/mental_health/suicide-prevention/ world_report_2014/en/ laccessed 9 Apr 2019).

2. Cooper J, Kapur N, Webb R, et al. Suicide after deliberate self-harm: a 4-year cohort study. Am J Psychiatry 2005; 162(2): 297-303.

3. Patton GC, Coffey C, Sawyer SM, et al. Global patterns of mortality in young people: a systematic analysis of population health data. Lancet 2009; 374(9693): 881-892.

4. Morgan C, Webb RT, Carr MJ, et al. Incidence, clinical management, and mortality risk following self harm among children and adolescents: cohort study in primary care. $B M$ 2017; 359: j4351.

5. Oude Voshaar RC, Cooper J, Murphy E, et al. First episode of self-harm in older age: a repor from the 10-year prospective Manchester SelfHarm project. J Clin Psychiatry 2011; 72(6): 737-743.

6. Hawton K, Harriss L. How often does deliberate self-harm occur relative to each suicide? A study of variations by gender and age. Suicide Life Threat Behav 2008; 38(6): 650-660.

7. Tyrell EG, Kendrick D, Sayal K, Orton E. Poisoning substances taken by young people: a population-based cohort study. $\mathrm{Br} J \mathrm{Gen}$ Pract 2018; DOI: https://doi.org/10.3399/ bjgp18X698897.

8. Daly C, Griffin E, Ashcroft DM, et al. Frequently used drug types and alcohol involvement in intentional drug overdoses in Ireland: a national registry study. Eur J Public Health 2018; 28(4): 681-686.

9. Harris EC, Barraclough B. Suicide as an outcome for mental disorders. A meta-analysis. Br J Psychiatry 1997; 170: 205-228.

10. Morgan C, Webb RT, Carr MJ, et al. Self-harm in a primary care cohort of older people: incidence, clinical management, and risk of suicide and other causes of death. Lancet Psychiatry 2018; 5(11): 905-912.

11. Hart JT. The inverse care law. Lancet 1971; 1(7696): 405-412

12. Carr MJ, Ashcroft DM, Kontopantelis E, et al. The epidemiology of self-harm in a UK-wide primary care patient cohort, 2001-2013. BMC Psychiatry 2016; 16: 53.

13. Carr MJ, Ashcroft DM, Kontopantelis E, et al. Clinical management following self-harm in a UK-wide primary care cohort. J Affect Disord 2016; 197: 182-188.

14. National Institute for Health and Care Excellence (NICE). Self-harm in over 8s: longer term management. CG133. https://uww.nice. org.uk/guidance/cg133 (accessed 9 Apr 2019).

15. National Institute for Health and Care Excellence. Do Not Do Recommendation. https://www.nice.org.uk/media/default/ sharedlearning/716_716donotdobookletfinal.pdf (accessed 9 Apr 2019).

16. Hawton $\mathrm{K}$, Bergen H, Simkin S, et al. Toxicity of antidepressants: rates of suicide relative to prescribing and non-fatal overdose. $\mathrm{Br} J$ Psychiatry 2010; 196(5): 354-358.

17. Coupland C, Hill T, Morriss R, et al. Antidepressant use and risk of suicide and attempted suicide or self harm in people aged 20 to 64: cohort study using a primary care database. BMJ 2015; 350: h517.

18. National Confidential Inquiry into Suicide and Homicide by People with Mental Illness (NCISH). Safer Services: a toolkit for specialist mental health services and primary care: 10 key elements to improve safety. 2017. http:// unw.champspublichealth.com/sites/default/ files/media library/Safer\%20services\%20A\%20 Toolkit.pdf laccessed 9 Apr 2019). 


\section{Editorials}

\section{Should GPs routinely screen for gambling disorders?}

\section{DISORDERED GAMBLING}

Gambling was reclassified from an impulse control disorder to a behavioural addiction in the DSM-5 (Diagnostic and Statistical Manual, 5th edn). ${ }^{1}$ Conservative estimates indicate that approximately $1 \%$ of the UK population exhibit gambling behaviour that warrants a diagnosis of 'disordered gambling', ${ }^{2}$ where disordered gambling refers to the useful term proposed in the DSM- $5^{2}$ re-classification encompassing 'problem', 'pathological', and 'compulsive' gambling.' The negative effects of disordered gambling can include mental health problems, financial crises, relationship breakdown, domestic violence, and self-harm or suicide, and tend to cluster with other high-risk behaviours such as smoking and drug taking. ${ }^{3}$

\section{GAMBLING AND PRIMARY CARE}

Disordered gamblers use NHS services extensively, being twice as likely to consult their GP, five times as likely to be hospital inpatients, and eight times as likely to have psychological counselling. ${ }^{4}$ Despite over-representation in healthcare services, patients are reluctant to disclose when gambling has become problematic. Primary care is an established context for addressing high-risk behaviours, although previous research reported 97\% of primary care, foundation, and mental health trusts in the UK did not provide specialist support for individuals seeking help for gambling problems, and only one trust offered dedicated specialist help for gamblers. ${ }^{5}$ Although most individuals with gambling problems do not seek specialist services, they do access general health care, therefore GPs have the opportunity to identify gambling disorders and refer affected patients to appropriate services before they reach crisis point.

\section{GP SURVEY}

There are limited data regarding disclosure of gambling problems by patients and awareness of gambling-related symptoms and treatment options among GPs. A recent UK study determined the extent of gambling problems among patients attending GP services, and reported a gambling disorder in $5 \%$ of patients. ${ }^{4}$ While reinforcing the potential for GP practices to be used for disorder detection, the study did not specially measure GPs' awareness of either

\section{spontaneous disclosure by problem gamblers is low}

gambling disorder symptoms or established care pathways for those experiencing the disorder. ${ }^{4}$ To this end, data were collected via an online survey from 85 GPs (34 female) from across the UK. Responders had been a GP for an average of 14.67 years (standard deviation [SD] 9.58, range 1-40 years).

GPs were asked to estimate the percentage of patients who had disclosed gambling, smoking, alcohol, and drug problems over the previous 6 months. Estimates indicate that $<1 \%$ of patients had disclosed gambling problems (mean 0.67, SD 2.30). By comparison, GPs estimated that approximately $25 \%$ of patients (mean 24.57, SD 23.80) admitted smoking. just under 10\% disclosed alcohol-related problems (mean 8.09, SD 14.18), and approximately $5 \%$ disclosed drug problems (mean 4.90, SD 9.98). Therefore, GPs estimate that patients are less likely to disclose gambling problems than substance use disorders. However, approximately $25 \%$ of GPs thought gamblers would spontaneously disclose gambling-related issues, identifying a disconnect: GPs significantly overestimate the likelihood of gamblers discussing gambling problems unprompted. This overestimation may be related to the fallacious assumption that patients will be willing to talk about anything during consultation. A similar trend is noted in sexual health, which has also been recognised as a difficult topic for discussion in consultation. ${ }^{6}$

Additionally, GPs were presented with a range of non-physiological symptoms associated with disordered gambling and asked which symptoms they would identify as indicative of a gambling disorder, based on prior knowledge and experience. Over $75 \%$ of responders identified financial hardship, anxiety and depression, preoccupation with gambling, stress, lies to conceal extent of gambling involvement, and previous failed attempts to cut down on gambling as symptoms indicative of gambling problems. GPs confirmed that they would look out for, on average, 7.89 $(S D=2.66)$ of the 11 listed symptoms; it would therefore appear that, within our sample, GPs are able to identify gambling symptoms.

However, when asked to identify a care pathway for a gambler, the answers are less encouraging, ranging from an offhand 'not a GP problem', or a basic 'tell them to just stop', to referring to other appropriate services. Overall, only 35\% of GPs surveyed were able to identify, from prior knowledge, a recognised gambling treatment provider.

\section{DISCUSSION}

As for other high-risk behaviours, primary care may provide an important environment for the early detection of gambling problems. ${ }^{7}$ As spontaneous disclosure by problem gamblers is low, GPs need to routinely ask about gambling addiction, just as they do for substance abuse. Early detection prior to crisis-driven help-seeking could potentially reduce the severe mental and physical health issues associated with disordered gambling, thus reducing demand on NHS services. In a recent think tank policy report, it was estimated that disordered gambling costs the NHS hundreds of millions of pounds through use of primary and secondary mental health services and hospital inpatient care. ${ }^{8}$ In the alcohol field, routine practice includes screening for instances and severity; for low-risk drinkers, brief intervention delivery is a cost-effective approach, whereas specialist referral is required for those who are alcohol dependent.? The same approach could be adopted for gambling, with significant cost implication for the NHS.

However, there are several points of contrast with substance use disorders that suggest the need for careful consideration of the role of GPs in identifying and addressing gambling disorders. For alcohol, severity dictates the level of intervention; in relation to gambling, however, there are no recognised strategies for identifying risk behaviours before serious harms have occurred (analogous to hazardous drinking), while existing screening tools are only suited for identifying disordered gambling 


\section{“... GPs can have a critical role in early detection of disordered gambling and in referral to enable early intervention before crisis point.}

(analogous to alcohol dependence). The Problem Gambling Severity Index $(P G S I)^{10}$ does offer a spectrum of harm categorisation; however, it was originally developed to measure general population problem gambling prevalence based on self-reported gambling behaviour rather than determinants of physiological or psychological harm, and may be too long to administer in a busy primary care practice. Shorter, more practical screening tools have been assessed for use in mental health services, although none in a UK population. ${ }^{11}$

Furthermore, on establishing the occurrence and severity of a gambling problem, GPs need to know the options available for treatment. Our pilot data suggest that, currently, this is not the case. It has been reliably demonstrated that psychological interventions for pathological gambling are consistently associated with favourable outcomes, both on a shortand long-term basis. ${ }^{12}$ Specialist service referrals could include the National Problem Gambling Clinic in London, online and telephone counselling through GamCare, or intensive residential therapy at the Gordon Moody Association. However, the best efforts of these treatment providers notwithstanding, the geographical sparsity and location, infrequency of support groups, and intensity of residential treatment result in the existing infrastructure for specialist gambling support being inadequate for the likely increase in referrals should GPs routinely screen for disordered gambling.

\section{CONCLUSION}

Despite the increasing number of gamblers in the UK and the overuse of NHS services for associated physical and mental health harms, ${ }^{2}$ external agency problem identification for problem gamblers is still very limited. As with alcohol and drug misuse, GPs can have a critical role in early detection of disordered gambling and in referral to enable early intervention before crisis point. However, in the absence of suitable identification and accessible intervention strategies for gambling, there are legitimate reasons for debate regarding the appropriate role of GPs.

\section{Amanda Roberts,}

Reader in Psychology, University of Lincoln College of Social Sciences, Lincoln.

\section{Henrietta Bowden-Jones,}

Consultant Psychiatrist, National Problem Gambling Clinic, London; Imperial College London, London.

\section{David Roberts,}

GP, Market Square Surgery, Waltham Abbey.

\section{Stephen Sharman,}

Research Fellow, University of East London, London.

\section{Provenance}

Freely submitted; externally peer reviewed.

\section{Competing interests}

The authors have declared no competing interests.

DOI: https://doi.org/10.3399/bjgp19X702329

\section{ADDRESS FOR CORRESPONDENCE}

\section{Amanda Roberts}

University of Lincoln College of Social Sciences, Brayford Pool, Lincoln LN6 7TS, UK.

Email: aroberts@lincoln.ac.uk

\section{REFERENCES}

1. American Psychiatric Association. Diagnostic and statistical manual of mental disorders [DSM-5]. 5th edn. Washington, DC: APA, 2013.

2. Wardle H, Moody A, Spence S, et al. British gambling prevalence survey 2010. 2011. https:// assets.publishing.service.gov.uk/government/ uploads/system/uploads/attachment_data/ file/243515/9780108509636.pdf laccessed 5 Apr 2019).

3. Roberts A, Sharman S, Coid J, et al. Gambling and negative life events in a nationally representative sample of UK men. Addict Behav 2017; 75: 95-102.

4. Cowlishaw S, Gale L, Gregory A, et al. Gambling problems among patients in primary care: a cross-sectional study of general practices. $\mathrm{Br}$ J Gen Pract 2017; DOI: https://doi.org/10.3399/ bjgp17X689905

5. Rigbye J, Griffiths MD. Problem gambling treatment within the British National Health Service. Int J Ment Health Addict 2011; 9(3): 276-281.

6. Hinchliff S, Gott M, Galena E. GPs' perceptions of the gender-related barriers to discussing sexual health in consultations: a qualitative study. Eur J Gen Pract 2004; 10(2): 56-60.

7. Sanju G, Gerada C. Problem gamblers in primary care: can GPs do more? Br J Gen Pract 2011; DOI: https://doi.org/10.3399/ bjgp11X567027.

8. Thorley C, Stirling A, Huynh E. Cards on the table: the cost to government associated with people who are problem gamblers in Britain. 2016. http://uww.ippr.org/publications/cardson-the-table laccessed 5 Apr 2019).

9. McCambridge J, Cunningham J. Against the odds: should GPs have any involvement with gambling problems? Br J Gen Pract 2007; 57(537): 327.

10. Ferris J, Wynne H. The Canadian problem gambling index. 2001. http://www.ccgr.ca/en/ projects/resources/CPGI-Final-Report-English. pdf (accessed 5 Apr 2019).

11. Dowling NA, Merkouris SS, Manning V, et al. Screening for problem gambling within mental health services: a comparison of the classification accuracy of brief instruments. Addiction 2018; 113(6): 1088-1104.

12. Pallesen S, Mitsem M, Kvale G, et al. Outcome of psychological treatments of pathological gambling: a review and meta-analysis. Addiction 2005; 100(10): 1412-1422. 